\title{
The ultrastructural features of the hemocapillary channel in common bile duct during the long-term influence of opioid in the experiment
}

\author{
I. I. Hirniak
}

\author{
Danylo Halytsky Lviv National Medical University \\ Corresponding author. E-mail: lvatseba@gmail.com
}

Paper received 23.06.20; Accepted for publication 13.07.20.

\author{
https://doi.org/10.31174/SEND-NT2020-233VIII28-11
}

\begin{abstract}
To define the features of the opioid effect on the morphological state of the hemocapillary channel of the common bile duct, a study was performed on 24 adult white male rats, which were injected for 6 weeks with the opioid «Nalbuphine»..The method of electron microscopy has been used. The results of the study showed that the first changes of the hemocapillary ultrastructure of the common bile duct wall developed after 2 weeks of nalbuphine administration to experimental animals, they increased during the following terms of the experiment and had all characteristic signs of angiopathy.
\end{abstract}

Keywords: bile duct, capillaries, ultrastructure, opioid, experiment.

Introduction. The morphology of the bile ducts remains one of the most current problems of modern medical science, as evidenced by a large number of scientific literature on the study of bile outflow paths under physiological norms and in various pathological conditions $[1,2]$. The damage of the bile duct mucous membrane epithelium due to autoimmune imbalance, viral or bacterial infection, toxic substances or developmental abnormalities, leads to severe structural changes in the liver, leading to high mortality [3]. Particular attention researchers focus on therapeutic and surgical treatment of bile duct pathology [4]. The number of bile duct surgeries has increased by $56 \%$ over the last 10 years (about 4,100 surgeries per year), with a postoperative mortality rate of $2.1 \%$ [5]. The widespread use of narcotic drugs in clinical practice to obtain analgesic and antiinflammatory effects requires a comprehensive morphological study of the organ structural organization under the influence of opioids [6].

A brief overview of publications on the topic. In recent years, the importance of drug-induced lesions of the liver and bile ducts has significantly increased [7]. Opioids are used to obtain an analgesic effect in patients with acute cholecystitis or acute cholangitis. [8]. Single studies are devoted to the influence of opioids on the morphological state of the digestive system organs [9, 10]. It has been found that in cholestatic liver diseases, the concentration of endogenous opioid peptides increases in the blood plasma, which indicates a close functional relationship between the hepatobiliary and opioid systems. It has been described the rapid progressive destruction of the bile ducts associated with the use of narcotic agents [11] and the effect of the ketamine opioid on the bile ducts $[12,13]$. Among nonobstructive etiologies of bile duct dilation, the opioid consumption predominates [14]. Opioids can cause an increase in basal pressure and frequency of phase contractions in the Oddi sphincter, which leads to the dilation of the bile ducts. In patients without clinical symptoms, the normal level of bilirubin and alkaline phosphatase, and without obstructive factors, it is described the relationship between increased bile duct diameter and opioid dependence. In professional literature, there are more and more reports that the structural changes of the organs, caused by the use of opioids, are preceded by the reorganization of the vessels in the hemomicrocirculatory channel of these organs, characteristic for microangiopathy [15]. We can predict the negative effect of opioids on the hemomicrocirculatory channel of the bile ducts. However, there are practically no studies on the structural organization of the hemocapillary channel of the bile duct walls under the conditions of opioid usage.

The aim of the study - to define the features of the ultrastructural organization of the hemocapillary channel in the common bile duct under the conditions of nalbuphine six-week administration in the experiment.

Materials and methods. The studies were performed on 24 adult white male rats, aged 4.5-5.5 months and weighing 180-200 g. Experimental animals were divided into 3 series: in the first series ( 5 animals), it has been studied the ultrastructure of the hemocapillary channel in the common bile duct after 2 weeks of nalbuphine administration, in $2^{\text {nd }}$ series of experiments ( 5 animals) at the ultramicroscopic level, the changes of the common bile duct microvessels were studied after 4 weeks of the experiment, and in $3^{\text {th }}$ series of experiments ( 5 animals), it has been found restructuring of the hemocapillary channel in the common bile duct in white rats after 6 weeks of nalbuphine administration. 9 white rats, which were injected with saline, were as control. Administration of nalbuphine was performed intramuscularly according to the following scheme: I week $-8 \mathrm{mg} / \mathrm{kg}$, II week - $15 \mathrm{mg} / \mathrm{kg}$, III week $20 \mathrm{mg} / \mathrm{kg}$,.IV week $-25 \mathrm{mg} / \mathrm{kg}, \mathrm{V}$ week $-30 \mathrm{mg} / \mathrm{kg}$,. VI week $-35 \mathrm{mg} / \mathrm{kg}$. The method of electron microscopy was used in the study..Ultrathin sections of the common bile duct were prepared on an ultramicrotome UZHTP-3 using glass knives. The tapes of silver or light lemon color sections were selected for the study. The sections were contrasted first in a $2 \%$ solution of uranyl acetate and then lead citrate..The study and photographing of the material were performed using a microscope UEMV-100 K at an acceleration voltage of $75 \mathrm{kV}$ and magnifications on the microscope screen of 1000-12000 x.

All animals were kept in the vivarium of Danylo Halytsky Lviv National Medical University, the experiments were conducted according to the provisions of the European Convention for the Protection of Vertebrate Animals used for Experimental and other Scientific Purposes (Strasbourg, 1986). 
Results and discussion. In electron microscopic examination of the hemocapillaries in the common bile duct of white rats after 2 weeks of nalbuphine administration, it has been revealed that the microvessels mostly retained their usual structure, but in some cases, there were capillaries with an enlarged lumen. The nuclei of single endothelial cells lost their proper shape (image 1). The perinuclear space was insignificantly enlarged. On the periphery, the cytoplasm of some endothelial cells is dilated, others indurated in the form of a strip, and represented by a large number of ribosomes, polysomes, and micropinocytic vesicles. The basement membrane integrity preserved, but in some areas, it is thickened and no clear outer contour. The granular endoplasmic reticulum is sometimes represented by dilated tubules containing single ribosomes, the Golgi complex - cisterns and a large number of bubbles with light content. In the matrix of mitochondria in weak electron density, the single dilated cristae are visible.

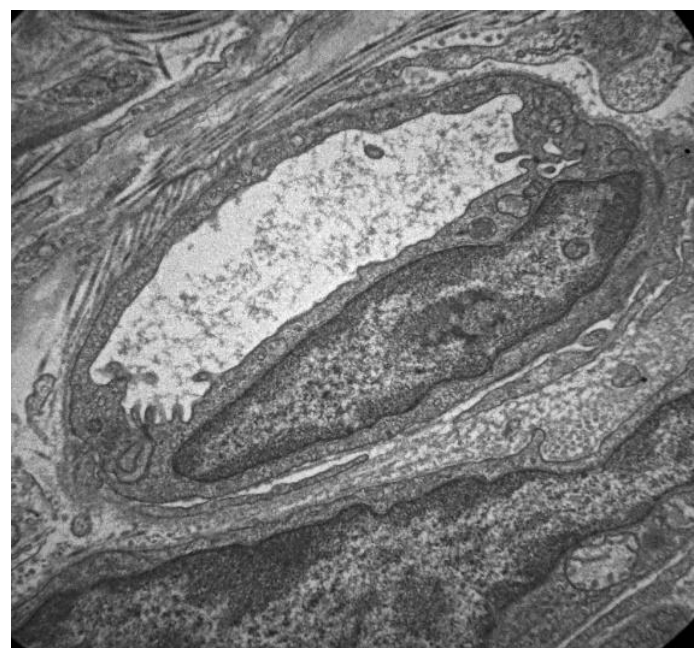

Image 1. Hemocapillary of the common bile duct wall in white rats after 2 weeks of nalbuphine administration. Electronic microphotography. The magnification: $x 4000$.

After 4 weeks of nalbuphine administration, in the hemocapillaries of the common bile duct wall, there have been found the significant changes - their wall thickened, the endothelial cells are swelled, their cytoplasm contained numerous mitochondria and free ribosomes. The nuclear part of the cytoplasm protruded into the lumen of the hemocapillary (image 2). In the nucleus of endothelial cells, the chromatin lumps are located on the periphery of the nucleus. In some places, the apical plasmalemma protruded into the lumen of the vessel and formed microvilli. The endoplasmic granular endoplasmic reticulum is represented by vacuoles, the Golgi complex contained dilated vesicles, in the mitochondria, it is a sparse matrix and single cristae.

After 6 weeks of the experiment, the lumen of most capillaries had an incorrect shape, there was significant edema with a reduced electron density of the cytoplasm of the endothelial cells (image 3 ). The contours of the nuclei are unclear, have the elongated shape with homogeneous chromatin, which was concentrated in lumps, located near the nucleolemma, and the number of nuclear pores is strongly decreased. The lumenal plasmalemma of endothelial cells with weak electron density had a protrusion and, in some places, formed microclasmatosis. Desmosomes between adjacent endothelial cells are destructured. The pericytes were characterized by unclear and uneven con- tours, the small intussusceptions were observed..In the lumen of microvessels, the accumulation of blood elements was observed; in the lumen of hemocapillaries, erythrocytes also had an altered shape (image 4). The basement membrane is thickened and acquired a „blurred" and unclear shape.

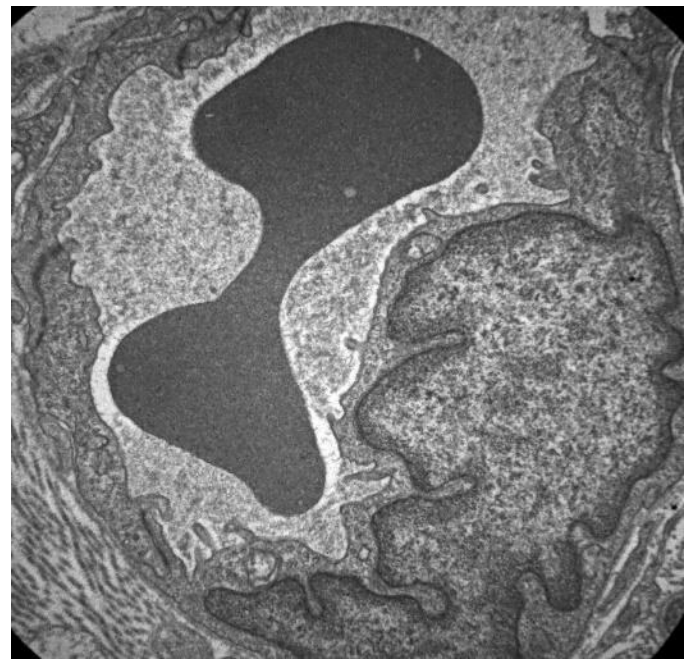

Image 2. Hemocapillary of the common bile duct wall in white rats after 4 weeks of nalbuphine administration. Electronic microphotography. The magnification: $\mathrm{x} 8000$.

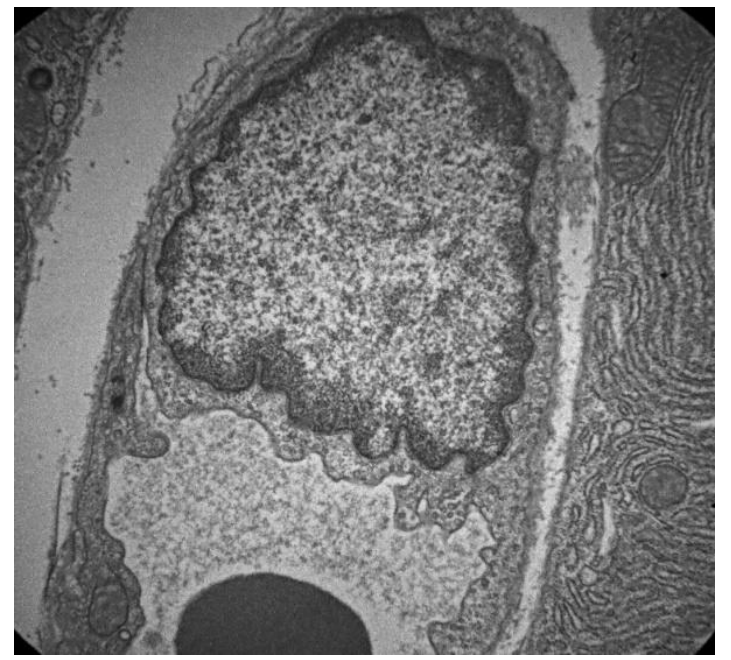

Image 3. Hemocapillary of the common bile duct wall in white rats after 6 weeks of nalbuphine administration. Electronic microphotography. The magnification: $x 4000$.

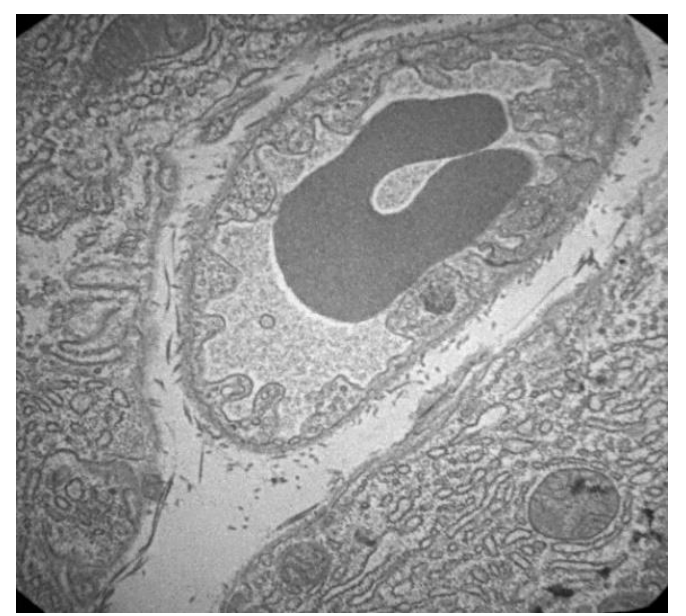

Image 4. Hemocapillary of the common bile duct wall in white rats after 6 weeks of nalbuphine administration. Electronic microphotography. The magnification: $x 4000$. 
Conclusions. The first changes of the hemocapillary ultrastructure in the common bile duct wall developed after 2 weeks of nalbuphine administration to experimental animals and they increased during the following terms of the experiment. In the conditions of 6-week nalbuphine administration, the main manifestations of microangiopathy of the common bile duct wall were: edema of endotheliocytes, the enlightenment of their cytoplasm, destructuring of the mitochondrial apparatus, vacuolation of granular endo- plasmic reticulum, protrusion of endotheliocytes into the lumen of capillaries, formation of cytoplasmic growths, shape change, fragmentation of endotheliocyte nucleus, formation of intussusception by nuclear membrane, condensed marginally placed chromatin, loosening, fragmentation of the basement membrane, change in the shape of the hemocapillary lumen, adhesion of blood elements to the wall of the microvessel.

\section{REFERENCES}

1. Giusto M, Barberi L, Di Sario F, Rizzuto E, Nicoletti C, Ascenzi F, Renzi A, et al. Skeletal muscle myopenia in mice model of bile duct ligation and carbon tetrachloride-induced liver cirrhosis. Physiol Rep. 2017;5(7):e13153. doi:10.14814/phy2.13153.

2. Sheen JM, Chen YC, Tain YL, Huang LT. Increased Circulatory Asymmetric Dimethylarginine and Multiple Organ Failure: Bile Duct Ligation in Rat as a Model. Int J Mol Sci. 2014;15(3):3989-4006. doi:10.3390/ijms15033989.

3. Hatano R, Akiyama K, Tamura A, Hosogi S, Marunaka Y, Caplan MJ, Ueno Y, et al. Knockdown of Ezrin Causes Intrahepatic Cholestasis by the Dysregulation of Bile Fluidity in the Bile Duct Epithelium in Mice. Hepatology. 2015;61(5):16601671. doi:10.1002/hep.27565.

4. Hatano R, Akiyama K, Tamura A, Hosogi S, Marunaka Y, Caplan MJ, Ueno Y, et al. Knockdown of Ezrin Causes Intrahepatic Cholestasis by the Dysregulation of Bile Fluidity in the Bile Duct Epithelium in Mice. Hepatology. 2015;61(5):16601671. doi:10.1002/hep.27565.

5. Zhou CG1 Wei BJ, Gao K, Dai DK, Zhai RY. Successful treatment of complex cholangiolithiasis following orthotopic liver transplantation with interventional radiology. World J Gastroenterol. $2015 \quad 14 ; 21(6): 2000-2004$ doi:10.3748/wjg.v21.i6.2000.

6. Voronkov M. Administration of nalbuphine to heroin addicts. Feasibility and short-term effects / M. Voronkov, D. Ocheret, S. Bondarenko // Heroin Addict Relat Clin Probl. - 2008. - 10, № 1. - P. 19-24.

7. Fenner EK, Boguniewicz J, Tucker RM, Sokol RJ, Mack CL. High Dose IgG Therapy Mitigates Bile Duct Targeted Inflammation and Obstruction in a Mouse Model of Biliary. Atresia Pediatr Res. 2014;76(1):72-80. doi:10.1038/pr.2014.46.

8. Farnia MR, Babaei R, Shirani F, Momeni M, Hajimaghsoudi M,
Vahidi E, Saeedi M. Analgesic effect of paracetamol combined with low-dose morphine versus morphine alone on patients with biliary colic:a double blind, randomized controlled trial. World J Emerg Med. 2016;7(1):2529.doi:10.5847/wjem.j.1920-8642.2016.01.004.

9. Baumeister D, Tojo LM, Tracy DK. Legal highs:staying on top of the flood of novel psychoactive substances. Ther Adv Psychopharmacol. doi: $10.1177 / 2045125314559539$.

10. Soleimanpour H, Safari S, Shahsavari Nia K, Sanaie S, Alavian SM. Opioid Drugs in Patients With Liver Disease: A Systematic Review. Hepat Mon. 2016;16(4):e32636. doi:10.5812/hepatmon.32636

11. Kim HY, Yang HK, Kim SH, Park JH. Ibuprofen Associated Acute Vanishing Bile Duct Syndrome and Toxic Epidermal Necrolysis in an Infant. Yonsei Med J. 2014;55(3):834-837. doi:10.3349/ymj.2014.55.3.834

12. Al-Nowfal A, Al-Abed YA. Chronic biliary colic associated with ketamine abuse. Int Med Case Rep J. 2016;9:135-137. doi: 10.2147/IMCRJ.S100648.

13. Sundaram V, Björnsson ES. Drug-induced cholestasis. Hepatol Commun. 2017;1(8):726-735. doi:10.1002/hep4.1088.

14. DeAngelis C, Marietti M, Bruno M, Pellicano R, Rizzetto M. Endoscopic ultrasound in common bile duct dilatation with normal liver enzymes. World J Gastrointest Endosc. 2015 Jul 10;7(8):799-805. doi:10.4253/wjge.v7.i8.799.

15. Mateshuk-Vatseba L, Kost A, Pidvalna U. Effect of Narcotic Analgesics on the Ultrastructure of the Eyeball (Experimental Study). Journal of Morphological Sciences. Georg Thieme Verlag KG; 2018 Dec 35(04):251-4. Available from: http://dx.doi.org/10.1055/s-0038-1676543 